\title{
Acute autonomic neuropathy following primary herpes simplex infection
}

\author{
BGR NEVILLE, ${ }^{*}$ GE SLADEN $\dagger$ \\ From the Department of Paediatric Neurology, ${ }^{*}$ and of Gastroenterology, $\dagger$ Guy's Hospital, London, UK
}

SUMMARY A 13-year-old girl presented with postural hypotension, severe abdominal pain and diarrhoea, parotid pain and a transient encephalopathy. There was evidence of an acute autonomic neuropathy and some electrophysiological evidence of a transient peripheral somatic neuropathy. The likely cause was primary herpes simplex infection.

There have been reports of eleven previous patients with acute autonomic neuropathy with ages ranging from 6 to 49 years since the original description in 1969.1-10 Diabetes melitus and infectious mononucleosis $^{8}$ were the likely cause in two patients. Although in three previous patients the CSF protein was raised, and in one there was an electron microscopic abnormality of a peripheral nerve, ${ }^{10}$ electrophysiological evidence of peripheral neuropathy has not been previously documented.

\section{Case history}

This previously normal girl presented in April 1980 aged 13 years with a four day history of painful mouth ulcers, anorexia and lassitude, and a two day history of drowsiness, headaches and photophobia. For one day she had had severe abdominal pain and vomiting.

\section{Encephalopathy}

The initial drowsiness, headache and photophobia with moderate neck stiffness lasted for only five days. A CSF protein was initially $650 \mathrm{mg} / \mathrm{l}$ with 4 white cells per cubic millimetre, and at six weeks was normal. EEG performed on day fifteen was abnormal with focal sharp and slow wave activity bilaterally, and six weeks later there was some improvement. A CT brain scan was normal.

\section{Peripheral neuropathy}

Despite early complaints of parasthesiae and weakness of the left hand, there were no objective signs. Electrophysiological studies showed borderline values but,

Address for reprint requests: Dr BGR Neville, Guy's Hospital, St Thomas Street, London SE1 9RT, UK

Received 16 May 1983 and in revised form 19 December 1983. Accepted 22 December 1983 when considered with the later test results were regarded as showing evidence of a mild generalised affection of large myelinated sensory and motor fibres.

$\begin{array}{llll} & \text { April } 1980 & \text { Sept. } 1982 & \text { Normal } \\ \text { L Sural SAP } & 11 \mu \mathrm{v} & 20 \mu \mathrm{v} & >10 \\ \text { R Radial SAP } & 18 \mu \mathrm{v} & 30 \mu \mathrm{v} & >20 \\ \text { R Median MNAP } & 20 \mu \mathrm{v} & 25 \mu \mathrm{v} & >20 \\ \begin{array}{l}\text { L Abductor } \\ \text { Hallucis MAP }\end{array} & 2.6 \mathrm{mv} & 7 \mathrm{mv} & >2\end{array}$

The CSF, IgG was $84 \mathrm{mg} / \mathrm{l}$ (normal range: 5-45) with a normal albumin level.

\section{Postural hypotension}

Severe postural hypotension limiting sitting and preventing standing was present for the first six weeks. This recovered over a total of six months. Initial blood pressure readings were $100 / 70 \mathrm{~mm} \mathrm{Hg}$ lying and unrecordable standing. Ephedrine was tried briefly without effect. Two years later she had transient symptoms on two occasions with heavy colds.

\section{Gastrointestinal problems and amenorrhoea}

She developed abdominal pain, vomiting, and profuse watery diarrhoea from day six, requiring intravenous replacement. During the first month her weight fell from $48 \mathrm{~kg}$ (at the 90 th centile) to $37 \mathrm{~kg}(<25$ th centile) and recovered slowly thereafter. Her menses ceased for eighteen months and resumed at a weight of $50 \mathrm{~kg}$, but were not regular thereafter. The colicky pains were very severe and recorded faecal weights varied from 200 to $800 \mathrm{~g}$ daily. During the initial phase, adequate intravenous hydration with $150 \mathrm{mM}$ saline, sufficient to produce satisfactory urinary sodium outputs ( $>20 \mathrm{mmol} /$ day), failed to correct the postural hypotension proving that this was not simply the result of salt depletion. A number of drugs were used and codeine phosphate was most effective in reducing the stool frequency.

There were never any striking physical signs, apart from variable dehydration and abdominal tenderness. Rectal and sigmoidoscopic examinations were normal to the 
recto-sigmoid junction. The following show no abnormality: radiography of abdomen, full blood count, Vickers profile, barium meal and follow through, faecal cultures and clostridium difficile toxin, salmonella serology, faecal fat excretion, urine/faecal screen for laxatives, GI hormone profile (including VIP, gastrin), thyroid function tests and scintilography; urinary porphyrins, glucose tolerance test, serum amylase (during attacks of pain), fasting serum cholesterol and triglycerides, serum magnesium levels. Calcitonin levels were persistently raised: $(\mathrm{N}=0 \cdot 08)$. Oct $1980-0.43 \mu \mathrm{g} / \mathrm{l} ;$ Nov 1980-1.63 $\mu \mathrm{g} / \mathrm{l} ;$ Jan 1981-1.13 $\mu \mathrm{g} / \mathrm{l}$; Aug 1981-2.32 $\mu \mathrm{g} / \mathrm{l}$. There was no clinical or genetic evidence of thyroid disease. The ESR was initially raised at $43 \mathrm{~mm}$ in the first hour and fell to $13 \mathrm{~mm}$ in the first hour within three weeks.

\section{Parotid pain}

From the time that she recommenced eating after the onset of this condition, she complained of pain behind the angles of the jaw on smelling or tasting food, particularly acidic flavours. This was worse on the right side and accompanied by profuse sweating on the right side of the face. Parotid duct dilatation on two occasions produced only transient improvement. A salivary scan, sialogram and investigation of the temporo-mandibular joint were normal. There was no response to carbamazepine or dilatation of the duct. This problem persists two and a half years after the onset of the condition but is waning in severity.

\section{Autonomic denervation}

In addition to postural hypotension, the ratio of the $\mathbf{R} R$ interval on standing between the 15 th and 30th beats was $0.995(\mathrm{~N}=1.25 \pm 0.05)$ but all other vascular reflexes were normal. $2.5 \%$ methacoline produced myosis. Schirmer's test showed only $5 \mathrm{~mm}$ of lacrimation bilaterally. Body temperature was raised $1^{\circ} \mathrm{C}$ producing sweating confined to a part of the trunk. Intradermal histamine on the abdomen produced a wheal and flare, and on the forearm produced a small flare and there was no response on the shin. Over six months later the methacoline response and sweating deficiency persisted but postural hypotension and tear production had recovered.

7 Primary herpes simplex infection

The extensive stomal ulceration recovered after ten days. Antibodies to herpes simplex were:

$\begin{array}{llll} & 7 \text { April } & 17 \text { April } & 21 \text { May } \\ & 1980 & 1980 & 1980 \\ \text { Serum } & <10 & 80 & 40 \\ \text { CSF } & & & <2\end{array}$

8 She developed very severe facial oedema in response to sunlight on one occasion two years after the original illness.

\section{Discussion}

Twelve patients including the present one have been reported with acute autonomic neuropathy.

Postural hypotension has occurred in nine and recovered completely. Ileus or constipation is the most frequent gastrointestinal problem which has occurred in eight, usually with complete recovery but, in one patient, this has required long-term parasympathomimetic drugs. The bladder problems have usually been those of an atonic bladder (in seven) requiring catheterisation in the acute phase with frequency of micturition in only two. Hypohidrosis was present in nine, almost always accompanied by a dry mouth and reduced tear production. An internal ophthalmoplegia was also reported in nine. Impotence occurred in all three adult males on whom full information was available. Parotid pain has only been present in one previous patient. ${ }^{5}$

The vomiting, abdominal pain and watery diarrhoea are ascribed to autonomic dysfunction with slow resolution over a 2 year period. Bowel disturbance is well recognised in patients with autonomic neuropathy. In diabetics both severe constipation and diarrhoea can occur. "In a review of 297 cases of chronic autonomic neuropathy from various causes in adults, $41 \%$ experienced constipation and only $5 \%$ diarrhoea. ${ }^{12}$ In Shy and Drager's original report, ${ }^{13}$ both cases had constipation with episodes of rectal incontinence. The two patients with an acute onset of autonomic neuropathy previously described both had severe abdominal pain and constipation, although one had profuse transient diarrhoea at the onset. The present case is unusual in that she had copious and persistent diarrhoea with much abdominal pain, but no constipation at any stage. Unfortunately no patho-physiological explanation for the diarrhoea was obtained in this case.

Diarrhoea can occur in patients with medullary carcinoma of the thyroid (MCT) with a raised level of calcitonin. There was no evidence of thyroid disease and calcitonin levels may be normally rather higher in children. Three patients have had evidence of encephalopathy, two mild as in the present patient, and one more severe with status epilepticus followed by temporal lobe epilepsy and recent memory defect.

The natural history of acute autonomic neuropathy has been complete recovery in three of the twelve patients, partial recovery in eight, and major symptoms have persisted in only one.

The features of interest in the present patient are the severity of the gastrointestinal problems, the presence of parotid pain and evidence of a mild encephalopathy. The original features are the demonstration of primary herpes simplex infection, and electrophysiological evidence of a mild demyelinating neuropathy.

We are grateful to $\mathrm{Dr} \mathrm{J}$ Payan, Department of Neurophysiology, Guy's Hospital, for the nerve conduction studies. 


\section{References}

' Anderson O, Lindberg J, Modigh K, Reske-Nielsen E. Subacute dysautonomia with incomplete recovery. Acta Neurol Scand 1972;48:510-9.

${ }^{2}$ Appenzeller O, Kornfeld M. Acute pandysautonomia. Arch Neurol 1973;29:334-9.

${ }^{3}$ Goulon M, Nouailhat F, Grosbuis S, Gajdos P. Hypotension. Revue Neurol (Paris) 1971;125:257-72.

${ }^{4}$ Hopkins A, Neville B, Bannister R. Autonomic neuropathy of acute onset. Lancet 1974;1:769-71.

${ }^{5}$ Okada F, Yamashita I, Suwa N. Two cases of acute pandysautonomia. Arch Neurol 1975;32:146-51.

6 Thomashefsky, AJ, Horowitz SJ, Feingold MH. Acute autonomic neuropathy. Neurology (Minneap) 1972;22:251-55.

${ }^{7}$ Wichser J, Vigayan N, Dreyfus PM. Dysautonomia: its significance in neurologic disease. Calif Med 1972;117:28-37.
${ }^{8}$ Yahr MD, Frontera AT. Acute autonomic neuropathy. Arch Neurol 1975;32:132-33.

9 Young RR, Asbury AK, Corbett JL, Adams RD. Pure pandysautonomia with recovery. Trans Am Neurol Assn 1969;94:355-7.

${ }^{10}$ Young RR, Asbury AK, Corbett JL, Adams RD. Pure pandysautonomia with recovery. Brain 1975; 98:613-36.

"Scarpello JHB, Sladen GE. Diabetes and the gut. Gut 1978;19:1153-62 (review).

${ }^{12}$ Hines S, Houston M, Robertson D. The clinical spectrum of autonomic neuropathy. Am J Med 1981;70:1091-6.

${ }^{13}$ Shy GM, and Drager GA. A neurological syndrome associated with orthostatic hypotension. A clinicopathological study. Arch Neurol 1960;2:511-27.

14 Becker NL, Silva OL, Snider RH, Moore CF, Geelhoed GW. The surgical implication of hypercalcitonemia. Surg Gynecol Obst 1982;154:897-908 (review). 